\title{
Sea ice led to poleward-shifted winds at the Last Glacial Maximum: the influence of state dependency on CMIP5 and PMIP3 models
}

\author{
Louise C. Sime ${ }^{1}$, Dominic Hodgson ${ }^{1}$, Thomas J. Bracegirdle ${ }^{1}$, Claire Allen ${ }^{1}$, Bianca Perren ${ }^{1}$, Stephen Roberts ${ }^{1}$, and \\ Agatha M. de Boer ${ }^{2}$ \\ ${ }^{1}$ British Antarctic Survey, Cambridge, UK \\ ${ }^{2}$ Bert Bolin Centre for Climate Research, Department of Geological Sciences, Stockholm University, Stockhom, Sweden
}

Correspondence to: Louise C. Sime (1sim@bas.ac.uk)

Received: 30 March 2016 - Published in Clim. Past Discuss.: 15 April 2016

Revised: 6 September 2016 - Accepted: 13 October 2016 - Published: 19 December 2016

\begin{abstract}
Latitudinal shifts in the Southern Ocean westerly wind jet could drive changes in the glacial to interglacial ocean $\mathrm{CO}_{2}$ inventory. However, whilst CMIP5 model results feature consistent future-warming jet shifts, there is considerable disagreement in deglacial-warming jet shifts. We find here that the dependence of pre-industrial (PI) to Last Glacial Maximum (LGM) jet shifts on PI jet position, or state dependency, explains less of the shifts in jet simulated by the models for the LGM compared with future-warming scenarios. State dependence is also weaker for intensity changes, compared to latitudinal shifts in the jet. Winter sea ice was considerably more extensive during the LGM. Changes in surface heat fluxes, due to this sea ice change, probably had a large impact on the jet. Models that both simulate realistically large expansions in sea ice and feature PI jets which are south of $50^{\circ} \mathrm{S}$ show an increase in wind speed around $55^{\circ} \mathrm{S}$ and can show a poleward shift in the jet between the PI and the LGM. However, models with the PI jet positioned equatorwards of around $47^{\circ} \mathrm{S}$ do not show this response: the sea ice edge is too far from the jet for it to respond. In models with accurately positioned PI jets, $\mathrm{a}+1^{\circ}$ difference in the latitude of the sea ice edge tends to be associated with a $-0.85^{\circ}$ shift in the $850 \mathrm{hPa}$ jet. However, it seems that around $5^{\circ}$ of expansion of LGM sea ice is necessary to hold the jet in its PI position. Since the Gersonde et al. (2005) data support an expansion of more than $5^{\circ}$, this result suggests that a slight poleward shift and intensification was the most likely jet change between the PI and the LGM. Without the effect of sea ice, models simulate poleward-shifted westerlies in warming climates and equatorward-shifted westerlies
\end{abstract}

in colder climates. However, the feedback of sea ice counters and reverses the equatorward trend in cooler climates so that the LGM winds were more likely to have also been shifted slightly poleward.

\section{Introduction}

The concentration of $\mathrm{CO}_{2}$ in the atmosphere decreases by $\sim 90$ parts per million between warm interglacial and cold glacial climate states due to oceanic storage of the excess carbon (Sigman et al., 2010). Mechanisms behind this enhanced ocean storage are still unresolved. One hypothesis invokes latitudinal shifts in the Southern Ocean westerly wind belt. An equatorward, or weaker, westerly wind jet could suppress deep water ventilation, leading to carbon becoming trapped in cold dense waters (Toggweiler et al., 2006; Sigman et al., 2010; Denton et al., 2010).

The evidence in favour of jet shifts driving increased glacial oceanic carbon storage though direct physical and biological carbon pumps is weak. Authors including Menviel et al. (2008), Tschumi et al. (2008), d'Orgeville et al. (2010), and Lee et al. (2011) have investigated the effect that wind jet shifts have on ocean circulation during the Last Glacial Maximum (LGM) using numerical models. In one of the most complete recent studies, Völker and Köhler (2013) simulated the impact of jet shifts with a full ocean general circulation model (MITgcm), spun up to simulate LGM conditions, and used a dissolved inorganic carbon package (MITgcm Group, 2013) to simulate carbon changes. They found small net ef- 
fects on atmospheric carbon, with a rise of only 3 to $9 \mathrm{ppm}$ $\mathrm{CO}_{2}$ under both a northward and a southward $10^{\circ}$ shift of the surface jet. These results are similar to those obtained using some simpler ocean models (Menviel et al., 2008; Tschumi et al., 2008; d'Orgeville et al., 2010). However, the effects on ocean circulation and biology are complex and non-linear, with competing effects from physical and biological carbon pumps. Thus it is difficult to know if these model-based studies are sufficiently accurate to constrain the $\mathrm{CO}_{2}$ impact of a specified wind shift. So whilst most, though not all (e.g. Lee et al., 2011), ocean and carbon modelling results do not support the idea that shifts in the westerly wind belt played a dominant role in coupling atmospheric $\mathrm{CO}_{2}$ rise and global temperature, there is, as yet, no definitive answer to this question.

Jet shifts have been proposed to modify other aspects of the climate- $\mathrm{CO}_{2}$ system. Iron-rich dust borne by Southern Hemisphere winds is thought to increase Southern Ocean productivity (Kohfeld et al., 2005). Lamy et al. (2014) show that large-scale southern hemispheric climate forcings, likely wind related, enhanced cold glacial period dust mobilisation in Australia, New Zealand, and Patagonia. Ferrari et al. (2014) hypothesise a Southern Ocean dividing latitude between negative and positive buoyancy forcing at the edge of the summer sea ice edge, with knock-on impacts for ocean dynamics. Völker and Köhler (2013) show that when the atmospheric jet shifts poleward, summer sea ice extends, likely due to enhanced heat loss to the atmosphere. Thus both dust and buoyancy forcing may provide an additional means for jet changes to influence glacial to interglacial climate shifts.

A wide range of palaeodata has been interpreted as evidence for glacial to interglacial jet shifts. These data include proxies, or direct measurements of, terrestrial moisture, dust deposition, sea surface temperatures, and ocean productivity. Kohfeld et al. (2013) find that purely based on these palaeodata, one can hypothesise a variety of wind change scenarios including: no change, a southward shift, and a northward shift. It remains an extraordinarily difficult task to constrain glacial to interglacial jet shifts and intensifications based on data alone (Hodgson and Sime, 2010). Whilst Sime et al. (2013) find that the moisture change palaeodata can be accurately modelled under a no jet shift scenario, Kohfeld et al. (2013) suggest that an equatorward jet shift, or intensification, could also be consistent with the majority of the palaeodata. Efforts to help solve this jet change problem using GCMs have benefitted from the fifth Coupled Model Intercomparison Project (CMIP5), specifically the third Paleoclimate Modelling Intercomparison Project (PMIP3), and its predecessor PMIP2 (Braconnot et al., 2007, 2012; Taylor et al., 2011). PMIP2 and PMIP3 have provided ensembles of LGM and pre-industrial (PI) climate simulations, where each model is run under the same boundary conditions, permitting inter-model comparisons and insight into crucial wind change mechanisms (e.g. Roche et al., 2012; Rojas, 2013; Chavaillaz et al., 2013; Sime et al., 2013; Liu et al., 2015).
Existing analyses of PMIP2 and PMIP3 LGM simulation ensembles show considerable inter-model disagreement in PI to LGM southern hemispheric jet changes (Rojas, 2013; Chavaillaz et al., 2013). This is despite the fact that nearly all CMIP5 models exhibit a poleward shift, and all models a strengthening, of the surface jet from 1900 to 2100 (Bracegirdle et al., 2013). Indeed Chavaillaz et al. (2013) find that future-warming scenario RCP4.5 (Representative Concentration Pathway 4.5) shifts in the $850 \mathrm{hPa}$ jet can be largely explained by tropospheric temperature differences between the southern high latitudes and the tropics. Bracegirdle et al. (2013) and Kidston and Gerber (2010) examine another aspect: state dependency for Southern Ocean jet shifts and intensity changes, where state dependency is defined as the dependence of jet shifts on the start jet position. Bracegirdle et al. (2013) find that for some oceanic sectors, particularly the Pacific, the starting position of the jet (state dependence) explains more than $85 \%$ of the jet shift variance found between the different CMIP5 future-warming scenario simulations. This implies that the start latitude of the jet is potentially a strong contender as an explanation for CMIP5-PMIP3 inter-model jet shift differences. Additionally, whilst tropical temperature changes dominate the future-warming wind changes, high-latitude temperature changes are as significant to the winds during the deglacial-warming (Chavaillaz et al., 2013). Sea ice is thus also highlighted as being particularly significant for the accurate jet simulations (Chavaillaz et al., 2013; Sime et al., 2013). Here we investigate past-cooling LGM state dependency, sea ice, and changes in the Southern Ocean westerly wind jet using CMIP5-PMIP3 output.

\section{Data: CMIP5-PMIP3 simulations}

CMIP5-PMIP3 PI and LGM simulations are run with full dynamic ocean and sea ice models. The LGM simulations all follow the PMIP3 protocol (https://wiki.lsce.ipsl.fr/pmip3/ doku.php/pmip3:design:21k:final): orbital parameters are set to their 21000 years ago values and concentrations of atmospheric greenhouse gases are set to $185 \mathrm{ppm}$ for $\mathrm{CO}_{2}$, $350 \mathrm{ppb}$ for $\mathrm{CH}_{4}$, and $200 \mathrm{ppb}$ for $\mathrm{N}_{2} \mathrm{O}$. All models use the PMIP3 LGM ice sheet or ICE5.2G ice sheet configurations (Chavaillaz et al., 2013). Simulations are run for long enough to allow the atmosphere and ocean to reach quasi-equilibrium (Braconnot et al., 2012; Rojas, 2013).

Models and simulations are shown in Table 1. For some models more than one realisation is available (i.e. the same model is run more than once with the same forcing). Where more than one realisation is available (indicated in Table 1), the mean of those realisations is used. Additionally, some models (e.g. GISS-E2-R-p150 and GISS-E2-R-p151) differ only slightly in their physics. In this case, as above, we use a mean of these model simulations. This yields a total of nine independent PMIP3 simulations. 
Table 1. List of all CMIP5-PMIP3 simulations used in this study. The individual simulations $(\mathrm{r}<N>\mathrm{i}<M>\mathrm{p}<\mathrm{L}>)$ formatted as shown below (e.g. "r3i1p21" with $\mathrm{r}$ for "realisation", i for "initialization method indicator", and p for "perturbed physics") distinguishes among closely related simulations by a single model.

\begin{tabular}{|c|c|c|c|c|c|}
\hline \multirow[b]{2}{*}{ Model } & \multirow[b]{2}{*}{ Institute } & \multicolumn{2}{|c|}{ Grid size } & \multicolumn{2}{|c|}{ Simulations } \\
\hline & & Lat. & Long. & Control (PI) & LGM \\
\hline CCSM4 & $\begin{array}{l}\text { National Center for Atmospheric Re- } \\
\text { search, US Dept. of Energy/NSF }\end{array}$ & 192 & 288 & r1i1p1,r2i1p1 & \\
\hline CNRM-CM5 & $\begin{array}{l}\text { Centre National de Recherches } \\
\text { Météorologiques/Centre Européen de } \\
\text { Recherche et Formation Avancée en } \\
\text { Calcul Scientifique, France }\end{array}$ & 128 & 256 & r1i1p1 (CNRM-CM5) & r1i1p1 (CNRM-CM5) \\
\hline COSMOS-ASO & $\begin{array}{l}\text { Max Planck Institute for Meteorology, } \\
\text { Hamburg, Germany }\end{array}$ & 48 & 96 & r1i1p1 (COSMOS-ASO) & r1i1p1 (COSMOS-ASO) \\
\hline FGOALS-g2 & $\begin{array}{l}\text { Institute of Atmospheric Physics, Chi- } \\
\text { nese Academy of Sciences and CESS, } \\
\text { Tsinghua University, China }\end{array}$ & 60 & 128 & r1i1p1 (FGOALS-g2) & r1i1p1 (FGOALS-g2) \\
\hline GISS-E2-R & $\begin{array}{l}\text { NASA Goddard Institute for Space } \\
\text { Studies, }\end{array}$ & 90 & 144 & $\begin{array}{l}\text { r1i1p142 (GISS-E2-R-p150) } \\
\text { r1i1p142 (GISS-E2-R-p151) }\end{array}$ & $\begin{array}{l}\text { r1i1p150 (GISS-E2-R-p150) } \\
\text { r1i1p151 (GISS-E2-R-p151) }\end{array}$ \\
\hline IPSL-CM5A-LR & Institut Pierre-Simon Laplace, France & 96 & 96 & r1i1p1 (IPSL-CM5A-LR) & r1i1p1 (IPSL-CM5A-LR) \\
\hline MIROC-ESM & $\begin{array}{l}\text { Japan Agency for Marine-Earth Sci- } \\
\text { ence and Technology, Atmosphere and } \\
\text { Ocean Research Institute (University of } \\
\text { Tokyo), and National Institute for Envi- } \\
\text { ronmental Studies, Japan }\end{array}$ & 64 & 128 & r1i1p1 (MIROC-ESM) & r1i1p1 (MIROC-ESM) \\
\hline MPI-ESM-P & $\begin{array}{l}\text { Max Planck Institute for Meteorology, } \\
\text { Hamburg, Germany }\end{array}$ & 96 & 192 & $\begin{array}{l}\text { r1i1p1 (MPI-ESM-P-p1) } \\
\text { r1i1p1 (MPI-ESM-P-p2) }\end{array}$ & $\begin{array}{l}\text { r1i1p1 (MPI-ESM-P-p1) } \\
\text { r1i1p2 (MPI-ESM-P-p1) }\end{array}$ \\
\hline MRI-CGCM3 & $\begin{array}{l}\text { Meteorological Research Institute, } \\
\text { Tsukuba, Japan }\end{array}$ & 160 & 320 & r1i1p1 (MRI-CGCM3) & r1i1p1 (MRI-CGCM3) \\
\hline
\end{tabular}

\subsection{Southern Ocean wind jet diagnostics}

The choice of Southern Ocean jet diagnostic can influence apparent glacial to interglacial wind change results (Liu et al., 2015). Previous authors have used surface winds (Kim et al., 2003), above-surface winds, or surface shear stress (Otto-Bliesner et al., 2006). Where sea ice replaces open water, each of these diagnostics shows a different response (Sime et al., 2013; Liu et al., 2015). Sea ice affects surface roughness and near-surface stratification of the boundary layer, this can lead to quite different results for glacial to interglacial changes in different wind diagnostics and shear stress (Fig. 1). For this reason, we concentrate on the above surface $(850 \mathrm{hPa})$ winds, given that any model specific specification of sea ice effects tends to have a lesser impact on this diagnostic (Sime et al., 2013). However, given the importance of surface wind speed and shear stress for driving the Southern Ocean and global ocean circulation and hence $\mathrm{CO}_{2}$ exchange, some discussion of all of these three wind diagnostics is included in this study.

When calculating jet intensity and position for each diagnostic, we use a cubic spline interpolation to quantify the jet maximum and determine its latitude. Jet shifts are defined here as PI to LGM changes in the latitudinal position of the zonal mean maximum in the jet. Data are regridded to a consistent $0.1^{\circ}$ resolution before these calculations are per- formed. In addition to these zonal mean diagnostics, we also assess individual ocean sectors results. In these cases, sectors are defined by longitude ranges as follows: Atlantic sector (290 to $20^{\circ}$ ), Indian sector $\left(20\right.$ to $150^{\circ}$ ), and Pacific sector $\left(150\right.$ to $\left.290^{\circ}\right)$. Jet diagnostics are calculated for the annual mean in the Southern Hemisphere $850 \mathrm{hPa}$ wind component; the annual mean $1000 \mathrm{hPa}$ westerly wind is used as an indicator for surface wind. This diagnostic is used in lieu of the $10 \mathrm{~m}$ surface westerly wind speed "uas" field, because "uas" is not available for LGM simulations for two CMIP5 models. We also calculate the zonal shear stress $\tau_{U}$, "jet" position and intensity. Required variables ("ua" and "tauu") were downloaded from the CMIP5 data archive between September and October in 2014.

All CMIP5 models show an equatorward bias in the present-day zonal mean surface jet position. The ensemble of present-day CMIP5 simulations show a mean equatorward bias of $3.3^{\circ}$ (inter-model standard deviation of $\pm 1.9^{\circ}$ ) in the position of the surface zonal mean jet (Bracegirdle et al., 2013; Swart and Fyfe, 2012). A bias is still present, but is reduced, in atmospheric-only simulations. This implies that sea surface temperature and sea ice errors, i.e. ocean-atmosphere coupling, tend to generate wind jet biases. Simulations of Southern Ocean winds are similar for both standard and hightop version models (Wilcox et al., 2012), which implies that inter-model differences in stratospheric resolution and repre- 

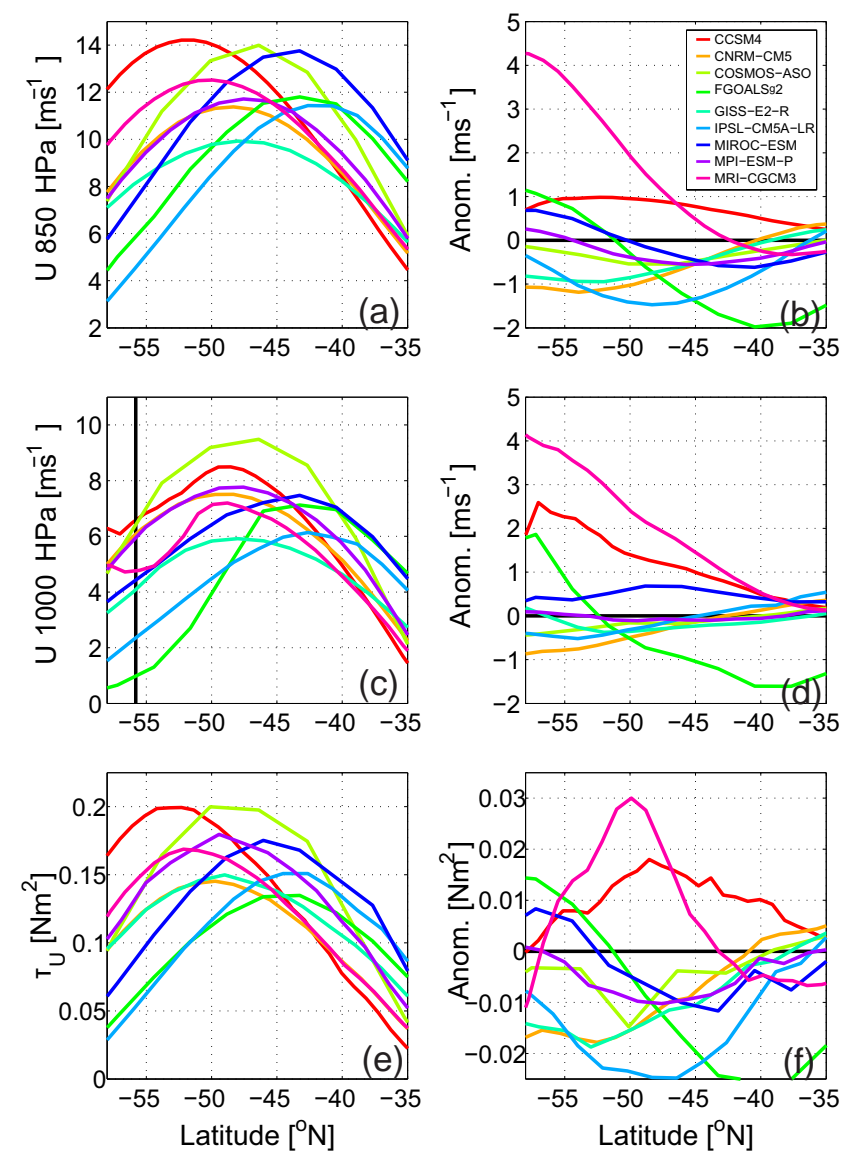

Figure 1. Zonal mean Southern Ocean winds. (a) PI wind speed $U$ at $850 \mathrm{hPa}$, (b) LGM - PI anomaly, (c) PI wind speed $U$ at $1000 \mathrm{hPa}$, and the ERA-Interim Bracegirdle et al. (2013) latitudinal position of the surface jet maximum to represent the observational position (d) and the $1000 \mathrm{hPa}$ LGM - PI anomaly, (e) PI surface shear stress $\tau_{U}$, and (f) the $\tau_{U}$ LGM - PI anomaly. Colours as shown in the legend in panel (b) denote the individual models. All values are annual means.

sentation may not be critical. The equatorward jet biases are mainly associated with the Indian and Pacific sectors.

\subsection{The sea ice edge}

Where available, sea ice concentration data were downloaded for the model simulations. The sea ice edge was calculated using a mean annual sea ice concentration of $15 \%$. For a few model simulations sea ice concentration data were not available. In this case a best fit relationship between sea surface temperature and sea ice edge, derived from the models where both output were available, was used to estimate the sea ice edge (COSMOS-ASO and IPSL-CM5A-LR).

\section{Results}

\subsection{Jet changes and state dependency}

We focus in this study on the PI and LGM CMIP5-PMIP3 simulations. Table 2 indicates a wide range of PI to LGM latitudinal jet shifts across the PMIP3 simulations, varying from +2.0 to $-4.5^{\circ}$ for the $850 \mathrm{hPa}$ jet. The mean $850 \mathrm{hPa}$ jet shift for the nine models is small: $-0.2^{\circ}$ (inter-model standard deviation of $\pm 2.1^{\circ}$ ). The mean surface jet shift for the nine models is $-0.9^{\circ}$ (inter-model standard deviation of $\pm 1.6^{\circ}$ ). The median shift for both 850 and $1000 \mathrm{hPa}$ is $0^{\circ}$. Similar inter-model variation appears in the jet intensity changes (Table 2).

Following the Bracegirdle et al. (2013) approach, we calculate state dependency for Southern Ocean jet shifts and intensity changes across the various oceanic sectors, i.e. the dependence of PI to LGM jet shifts with PI jet position. Feedbacks within the troposphere have been used to explain state dependence in previous studies (e.g. Kidston and Gerber, 2010). We find that state dependency can explain up to $56 \%$ of the variance in PI to LGM jet shifts in the Atlantic $\left(r=-0.75, N=9\right.$, for $\left.\tau_{U}\right)$ and $41 \%$ in the Indian Ocean $\left(r=-0.64, N=9\right.$, for $\left.\tau_{U}\right)$. State dependency is much weaker in the Pacific; here any influence is negligible. 850 and $1000 \mathrm{hPa}$ results are always very similar (not shown). We find state dependence is stronger for the $\tau_{U}$ jet than the $850 \mathrm{hPa}$ jet (Fig. 2) due largely to the MRI-CGCM3 $850 \mathrm{hPa}$ outlier. With the anomalous MRI-CGCM3 $850 \mathrm{hPa}$ wind result removed from the calculation, we obtain similar results between $850 \mathrm{hPa}$ and $\tau_{U}$. For the whole of the Southern Ocean, the variance explained by state dependency is $38 \%$ $\left(r=-0.62, N=9\right.$, for $\left.\tau_{U}\right)$.

Whilst these CMIP5-PMIP3 results bear similarities to the Bracegirdle et al. (2013) CMIP5-RCP8.5 analysis of state dependence, they also show distinct differences. Over the Atlantic sector Bracegirdle et al. (2013) find that the correlation, calculated between present-day and RCP8.5 CMIP5 output, is relatively weak $(r=-0.39)$ compared with the correlations over the Indian sector $(r=-0.50)$ and Pacific sector $(r=-0.91)$. Interestingly, Bracegirdle et al. (2013) also find that correlation results over the Atlantic are conditional on omitting model MRI-CGCM3, which is again an influential outlier due to jumps in jet position.

For jet intensity Bracegirdle et al. (2013) find the state dependence is generally weaker than for position; we find a similar result here. The state dependency in intensity change can explain only $25 \%\left(r=-0.50, N=9\right.$, for $\left.\tau_{U}\right)$ of the PI to LGM change.

This analysis indicates that, whilst state dependence plays a role in determining deglacial-warming jet shifts and intensity changes, overall the influence of state dependency alone is much weaker compared with future-warming climate change scenarios. This implies that other factors must also be important in determining the LGM wind changes; we 
Table 2. The Southern Ocean westerly winds jet position, jet strength, and PI to LGM changes in jet position and strength.

\begin{tabular}{|c|c|c|c|c|c|c|c|c|c|c|c|c|}
\hline \multirow[b]{2}{*}{ Model } & \multicolumn{3}{|c|}{ Location PI jet $\left({ }^{\circ} \mathrm{N}\right)$} & \multicolumn{3}{|c|}{ Jet shift $\left({ }^{\circ}\right)$} & \multicolumn{3}{|c|}{ Maximum in PI Jet } & \multicolumn{3}{|c|}{ Jet strength change } \\
\hline & $\begin{array}{r}850 \mathrm{hPa} \\
\left({ }^{\circ} \mathrm{N}\right)\end{array}$ & $\begin{array}{r}1000 \mathrm{hPa} \\
\left({ }^{\circ} \mathrm{N}\right)\end{array}$ & $\begin{array}{r}\tau_{U} \\
\left({ }^{\circ} \mathrm{N}\right)\end{array}$ & $\begin{array}{r}850 \mathrm{hPa} \\
\left({ }^{\circ}\right)\end{array}$ & $\begin{array}{r}1000 \mathrm{hPa} \\
\left({ }^{\circ}\right)\end{array}$ & $\begin{array}{l}\tau_{U} \\
\left(^{\circ}\right)\end{array}$ & $\begin{array}{r}850 \mathrm{hPa} \\
\left(\mathrm{ms}^{-1}\right)\end{array}$ & $\begin{array}{r}1000 \mathrm{hPa} \\
\left(\mathrm{ms}^{-1}\right)\end{array}$ & $\begin{array}{r}\tau_{U} \\
\left(\mathrm{Nm}^{-2}\right)\end{array}$ & $\begin{array}{r}850 \mathrm{hPa} \\
\left(\mathrm{ms}^{-1}\right)\end{array}$ & $\begin{array}{r}1000 \mathrm{hPa} \\
\left(\mathrm{ms}^{-1}\right)\end{array}$ & $\begin{array}{r}\tau_{U} \\
\left(\mathrm{Nm}^{-2}\right)\end{array}$ \\
\hline CCSM4 & -51.8 & -49.0 & -52.3 & 0.0 & -1.4 & 0.9 & 14.2 & 8.53 & 0.199 & 0.99 & 1.50 & 0.011 \\
\hline CNRM-CM5 & -48.3 & -48.4 & -49.7 & 1.4 & 0.1 & 1.3 & 11.4 & 7.51 & 0.145 & -0.84 & -0.38 & -0.015 \\
\hline COSMOS-ASO & -46.4 & -46.4 & -50.1 & 0.0 & 0.0 & 3.7 & 14.0 & 9.49 & 0.20 & -0.54 & -0.18 & -0.006 \\
\hline FGOALS g2 & -43.3 & -43.3 & -43.3 & -2.7 & -2.7 & -2.7 & 11.8 & 7.12 & 0.135 & -1.48 & -1.21 & -0.018 \\
\hline GISS-E2-R & -48.0 & -48.0 & -49.0 & 2.0 & 0.0 & 0.0 & 9.9 & 5.92 & 0.150 & -0.67 & -0.31 & -0.014 \\
\hline IPSL-CM5A-LR & -42.6 & -42.6 & -42.7 & 1.9 & 0.0 & 0.1 & 11.4 & 6.14 & 0.151 & -0.84 & 0.12 & -0.018 \\
\hline MIROC-ESM & -43.3 & -43.3 & -46 & 0.0 & 0.0 & -0.1 & 13.8 & 7.47 & 0.175 & -0.58 & 0.54 & -0.010 \\
\hline MPI-ESM-P & -47.6 & -47.6 & -49.4 & 0.0 & 0.0 & 0.0 & 11.7 & 7.77 & 0.180 & -0.50 & -0.07 & -0.010 \\
\hline MRI-CGCM3 & -49.9 & -48.8 & -52.1 & -4.5 & -4.5 & 1.1 & 12.5 & 7.20 & 0.169 & 2.70 & 3.03 & 0.027 \\
\hline MEAN & -46.8 & -46.4 & -48.3 & -0.21 & -0.94 & 0.48 & 12.3 & 7.46 & 0.167 & -0.196 & 0.34 & -0.006 \\
\hline
\end{tabular}
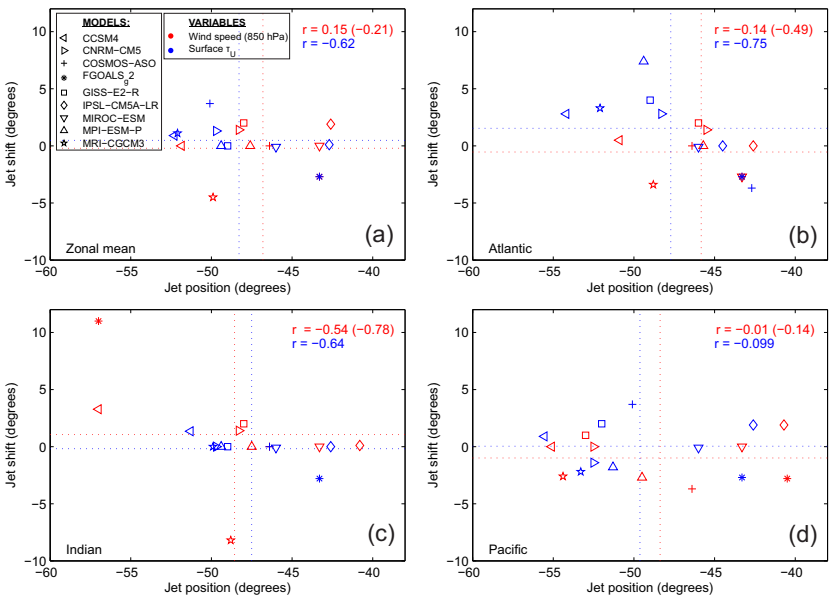

Figure 2. The state dependence of jet latitudinal shifts. (a) Scatter plot of PI annual mean Southern Ocean jet position versus LGM minus PI change in the CMIP5-PMIP3 models. (b), (c), and (d) show the same but for individual ocean sectors: Atlantic, Indian, and Pacific, as marked. The Atlantic sector is defined as 290 to $20^{\circ}$, the Indian as 20 to $150^{\circ}$, and the Pacific as 150 to $290^{\circ}$. Individual symbols indicate individual models, as marked in the legend in panel (a). The jet is defined using the zonal $850 \mathrm{hPa}$ wind speed (red) and surface shear stress (blue). Dashed lines indicate the model mean position and model mean shift for each panel. Specified $r$ values indicate the correlation coefficient; bracketed $850 \mathrm{hPa}$ $r$ values are calculated excluding the MRI-CGCM3 model. Correlation coefficients and relationships using $1000 \mathrm{hPa}$ "surface wind speeds" are almost identical to those using $850 \mathrm{hPa}$.

now look at the factors which are most likely to drive these changes.

\subsection{The impact of sea ice}

The most recent compilation of LGM sea surface temperature data is the MARGO dataset (MARGO Project Members, 2009). Although the coverage of MARGO data is good in tropical regions, it is sparse poleward of $40^{\circ} \mathrm{S}$ (MARGO
Project Members, 2009). However, Gersonde et al. (2005) provide LGM sea surface temperature and sea ice data from 122 Southern Ocean sediment core sites. These data suggest that LGM sea ice extended in the Atlantic and Indian sector to close to $47^{\circ} \mathrm{S}$ and in the Pacific sector to $57^{\circ} \mathrm{S}-\mathrm{a}$ PI to LGM equatorward expansion of between 7 and $10^{\circ}$ in latitude. This is a large change, particularly compared with the sea ice changes which occur during most future-warming scenario CMIP5 simulations.

All CMIP5-PMIP3 models for which we can retrieve sea ice output show an LGM expansion of sea ice in the Southern Hemisphere (Table 3). There is considerable variability between the models. Expansions range between 2.1 and 7.0 $0^{\circ}$ (Fig. 4, Table 3). Only two models, CCSM4 and MRICGCM3 (with Gersonde et al. (2005) data agreements of 87 and $88 \%$; see Appendix A), appear to yield an accurate simulation of LGM sea ice extent (Table 3) and some of the largest equatorward expansions of sea ice at 5.6 and $7.0^{\circ}$, respectively.

Changes in sea ice extent are associated with relatively strong surface heat flux anomalies, which can be as large as $100 \mathrm{~W} \mathrm{~m}^{-2}$ (Alexander et al., 2004). A strong non-linearity of wind response can thus be generated, dependent on the location of the resultant changes in meridional temperature gradients in the atmosphere. For example, surface cooling due to an expansion of sea ice causes an anomalous increase in the meridional temperature gradient adjacent to the newly ice-covered ocean. If this increased gradient lies immediately poleward of the jet and its associated baroclinic zone, it can be more effective at influencing developing baroclinic waves and the latitude of the jet. Support for this idea is also found in the results of Chen et al. (2010) and Brayshaw et al. (2008), where changes in surface heat fluxes have the largest impact when they are approximately co-located with the maximum in the meridional temperature gradient.

If we look at changes in CMIP5-PMIP3 sea ice along with westerly winds and meridional temperature gradients throughout the atmosphere, we see evidence of this effect (Figs. 5 and 6). Although, broadly, larger increases in tem- 
Table 3. The model-data agreement from the sea ice edge latitude, the mean zonal sea ice edge latitude, and the PI to LGM jet shift. Simulation results are bi-linearly interpolated to each Gersonde et al. (2005) observation site. Model-data agreement is then calculated by classing simulated sea ice as present or absent, analogous to the exact metric defined by Sime et al. (2013). A simple agreement percentage metric is then calculated using the equivalent Gersonde et al. (2005) sea ice (present or absent) observations.

\begin{tabular}{lrr|rrr}
\hline \multirow{2}{*}{ Model } & \multicolumn{2}{c|}{ Sea ice agreement } & \multicolumn{2}{|c}{ Sea ice edge position } & Sea ice shift \\
& PI & LGM & PI & LGM & LGM-PI \\
\cline { 2 - 5 } & $(\%)$ & $(\%)$ & $\left({ }^{\circ} \mathrm{N}\right)$ & $\left({ }^{\circ} \mathrm{N}\right)$ & $\left({ }^{\circ}\right)$ \\
\hline CCSM4 & 94 & 87 & -58.2 & -52.6 & 5.57 \\
CNRM-CM5 & 98 & 56 & -61.6 & -59.3 & 2.27 \\
COSMOS-ASO & $\mathrm{NaN}$ & $\mathrm{NaN}$ & $\mathrm{NaN}$ & $\mathrm{NaN}$ & $\mathrm{NaN}$ \\
FGOALS-g2 & 85 & 37 & -59.2 & -56.4 & 2.78 \\
GISS-E2-R & 85 & 37 & -63.3 & -61.2 & 2.05 \\
IPSL-CM5A-LR & $\mathrm{NaN}$ & $\mathrm{NaN}$ & $\mathrm{NaN}$ & $\mathrm{NaN}$ & $\mathrm{NaN}$ \\
MIROC-ESM & 85 & 37 & -60.3 & -57.4 & 2.91 \\
MPI-ESM-P & 87 & 59 & -64.3 & -57.8 & 6.57 \\
MRI-CGCM3 & 92 & 88 & -61.1 & -54.1 & 7.04 \\
\hline
\end{tabular}
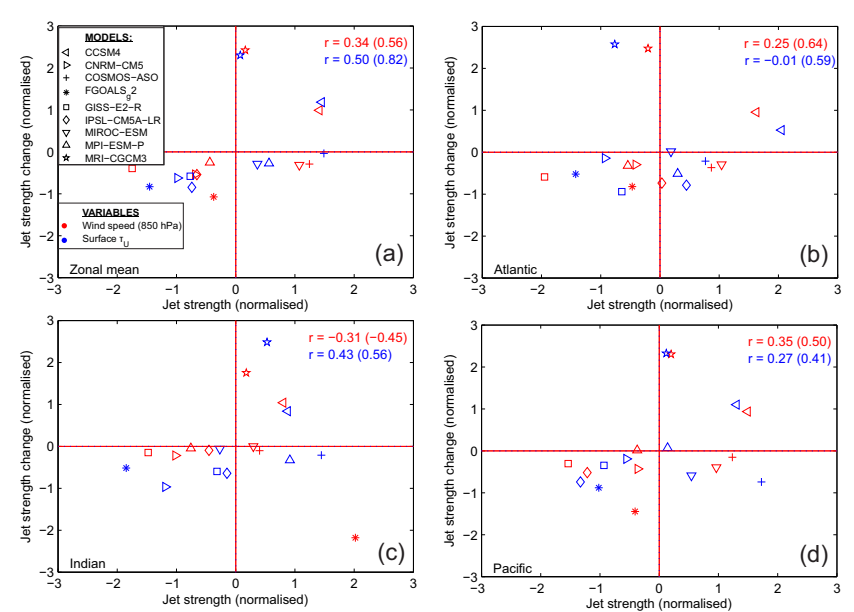

Figure 3. The state dependence of jet intensity (wind speed) changes. (a) Scatter plot of PI annual mean Southern Ocean jet strength versus LGM minus PI change in the CMIP5-PMIP3 models. Zonal mean (a), Atlantic sector (b), Indian sector (c), and $\mathrm{Pa}$ cific sector (d). Results are normalised by subtracting the mean of all models, and dividing through by the standard deviation of all models. Caption and results as Fig. 2.

perature gradient over the troposphere give larger westerly wind increases over the troposphere, this is actually because increases in horizontal temperature gradient lead to increases in westerly wind with height. These wind changes are generally quite small near the surface and either increase or decrease with height, depending on the sign of the temperature gradient change.

When looking at all models, there are some commonalities in the meridional structure in wind and temperature gradient changes. Between the top and $200 \mathrm{hPa}$ level, poleward of $50^{\circ} \mathrm{S}$ the temperature gradient increases resulting in an increase in westerly wind speed, $U$. Equatorward of $50^{\circ} \mathrm{S}$ the temperature gradient tends to decrease, with the strongest decrease between 50 and $300 \mathrm{hPa}$. Upper and mid-tropospheric $U$ also decreases in all models equatorward of around $50^{\circ} \mathrm{S}$. Below $400 \mathrm{hPa}$ there tends to be an increase in the meridional temperature gradient poleward of around $40^{\circ} \mathrm{S}$, but there is considerable inter-model variability in the details of the temperature gradient changes and in associated wind changes.

As the above implies, we find that the key differences in westerly winds and meridional temperature gradients changes are a function of state dependence and sea ice. Indeed, based on state dependence (PI jet position) and sea ice changes, models can be roughly classed into four groups. CCSM4 and MRI-CGCM3, in the first group (Figs. 5a, b and $6 \mathrm{a}, \mathrm{b}$ ), both simulate large expansions in sea ice (of 5.6 and $7^{\circ}$, respectively) and feature the most southerly positioned jets (at $51^{\circ} \mathrm{S} \pm 1.1^{\circ}$ ). This jet position tends to leave $U$ sensitive to expansions in sea ice. The large increases in the meridional temperature gradient, especially around $55^{\circ} \mathrm{S}$ from 1000 to about $650 \mathrm{hPa}$, thus tally with the increases in $U$ around these latitudes and also result in a PI to LGM poleward shift in the jet in both models, especially in MRICGCM3.

In the second group, whilst GISS-ER-R and CNRM-CM5 (Figs. 5c, d and 6c, d) have PI jets which are positioned relatively far to the south (at $48^{\circ} \mathrm{S} \pm 0.3^{\circ}$ ), both feature rather small LGM expansions in sea ice (of around $2^{\circ}$ ). The resultant small polar atmospheric cooling causes little change in the meridional temperature gradient. $U$ tends to weaken over the Southern Ocean latitudes, likely due to the overall atmospheric cooling. These two models show a slight equatorward shift in their jets between the PI and the LGM.

In the third group, COSMOS-ASO and MPI-ESM-P (Figs. 5e, $\mathrm{f}$ and 6e, f) have PI jets positioned at $47^{\circ} \mathrm{S} \pm 0.6^{\circ}$ and feature quite large LGM expansions in sea ice (of 5 and $6^{\circ}$, respectively). The position of these jets makes these mod- 


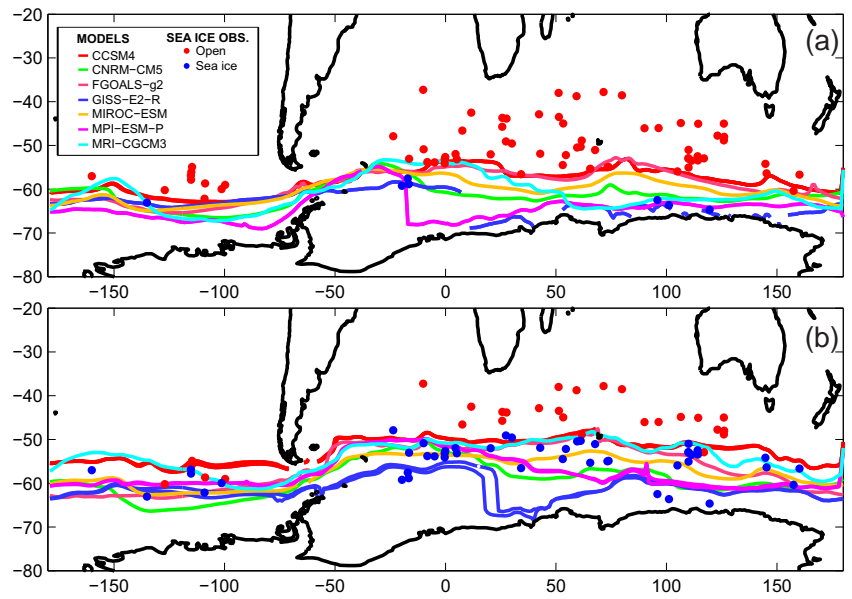

Figure 4. Sea ice from models and the Gersonde et al. (2005) observations for (a) the PI and (b) the LGM. Coloured dots show open water (red) and inferred sea ice (blue). The differing coloured lines show the annual mean $15 \%$ sea ice extent for individual models. See legend for colours.

els less sensitive to the LGM expansion of sea ice: they show a slight weakening of $U$ and no jet shifts. It seems that the storm track and its associated baroclinic zone are not significantly affected by these sea ice increases, or by associated meridional temperature gradient changes, because they happen far poleward of the baroclinic jet zone.

In the last group, FGOALS-G2, IPSL-CM5A-LR, and MIROC-ESM (Figs. 5g, h, i and 6g, h, i) all have very northerly positioned PI jets (at $43^{\circ} \mathrm{S} \pm 0.5^{\circ}$ ), due they also all show a rather small (less than $3^{\circ}$ ) LGM increase in sea ice extent. The jets in these models thus seem to be responding to influences other than sea ice: possibly tropical changes or sea surface temperature changes nearer $43^{\circ}$ have more impact. Chavaillaz et al. (2013) find a quasi-linear relationship between the jet shifts and tropical temperature changes in the atmosphere, where polar temperatures are held constant, suggesting that tropical changes may be a stronger influence on these models.

\subsubsection{The relationship between sea ice extent and jet position}

In simulations with more poleward (i.e. accurately) positioned PI jets, the examination above of jet and sea ice changes suggests that PI to LGM wind changes are strongly related to sea ice extent. Figure 7a shows that the PI jet position is inversely related to sea ice extent in models with the most accurately positioned PI jets. We find that an equatorwards sea ice edge correlates with a poleward jet position $(r=-0.95$ for the PI, and $r=-0.91$ for the LGM). Whilst correlations are strongest for $850 \mathrm{hPa}$ winds, similar results are obtained using $1000 \mathrm{hPa}$ and $\tau_{U}(r<-0.80)$.
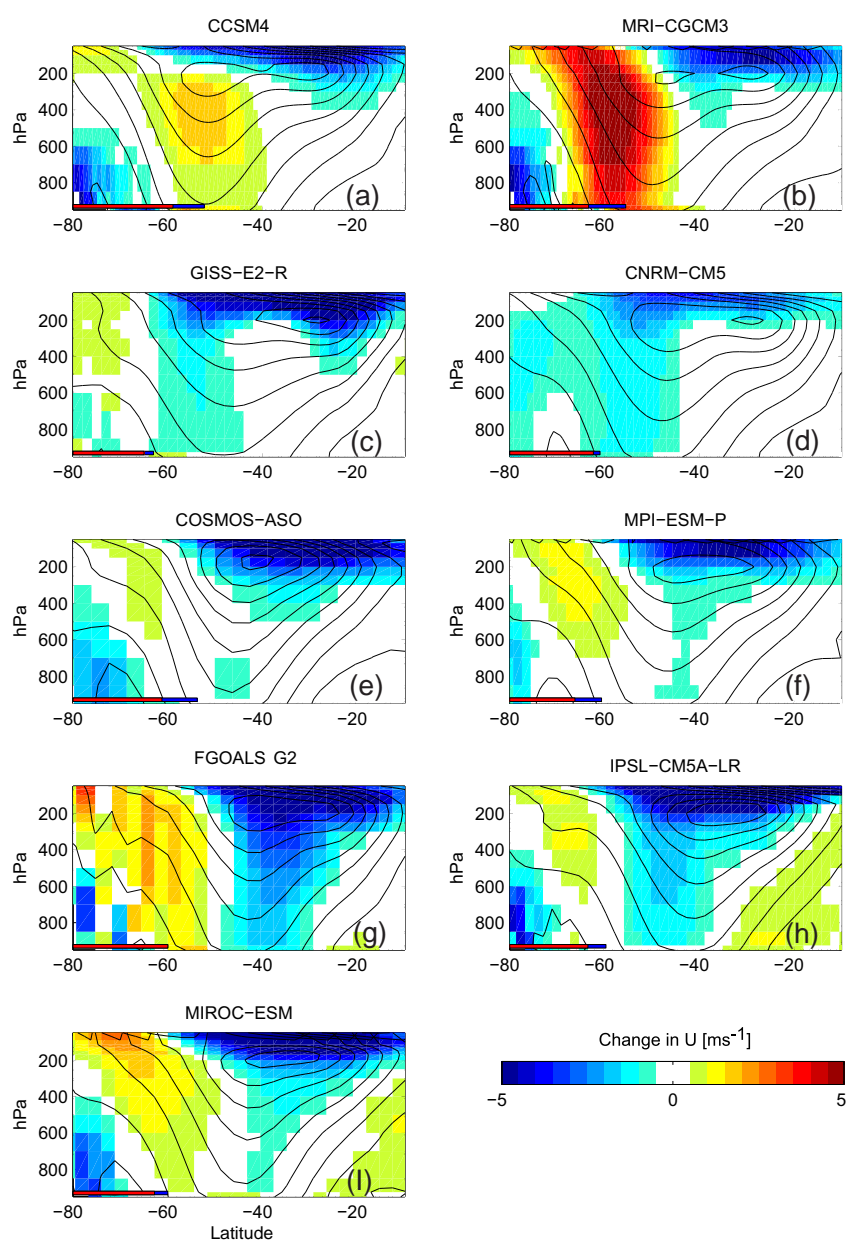

Figure 5. Change is the zonal mean wind velocity component in the westerly direction $U$ (LGM - PI) throughout the atmosphere (shaded). Black contours show mean $U$ for the PI. Red and blue bars at the bottom left of each panel indicate the extent of the zonal mean sea ice for the PI and LGM, respectively. Individual panels are labelled to indicate individual models. All values are annual means.

In terms of PI to LGM jet shifts, if we apply a linear least-squares fit, we find that a $1^{\circ}$ difference in the sea ice edge suggests a $-0.85^{\circ}$ shift in the $850 \mathrm{hPa}$ jet $(r=-0.80$; $N=5$ ). These results are heavily influenced by, but not entirely dependent on, the MRI-CGCM3 model. This model features the largest $7^{\circ}$ expansion of the sea ice and a large $4.5^{\circ} \mathrm{S}$ poleward shift in the $850 \mathrm{hPa}$ jet (Fig. 7; Table 3). Without this model result included in the calculation, a $1^{\circ}$ difference in the sea ice edge still suggests a $-0.43^{\circ}$ shift in the $850 \mathrm{hPa}$ jet $(r=-0.96 ; N=4)$. However, as the section above indicates, this relationship only applies to models which have jets which are relatively accurately positioned, i.e. those which are sensitive to the impact of sea ice changes; if the model has a jet which sits equatorward of $47^{\circ} \mathrm{S}$ then the relationship breaks down. This relationship also fits with the study of Kidston et al. (2011), who found that the jet shifts significantly poleward when the sea ice extent is substantially 

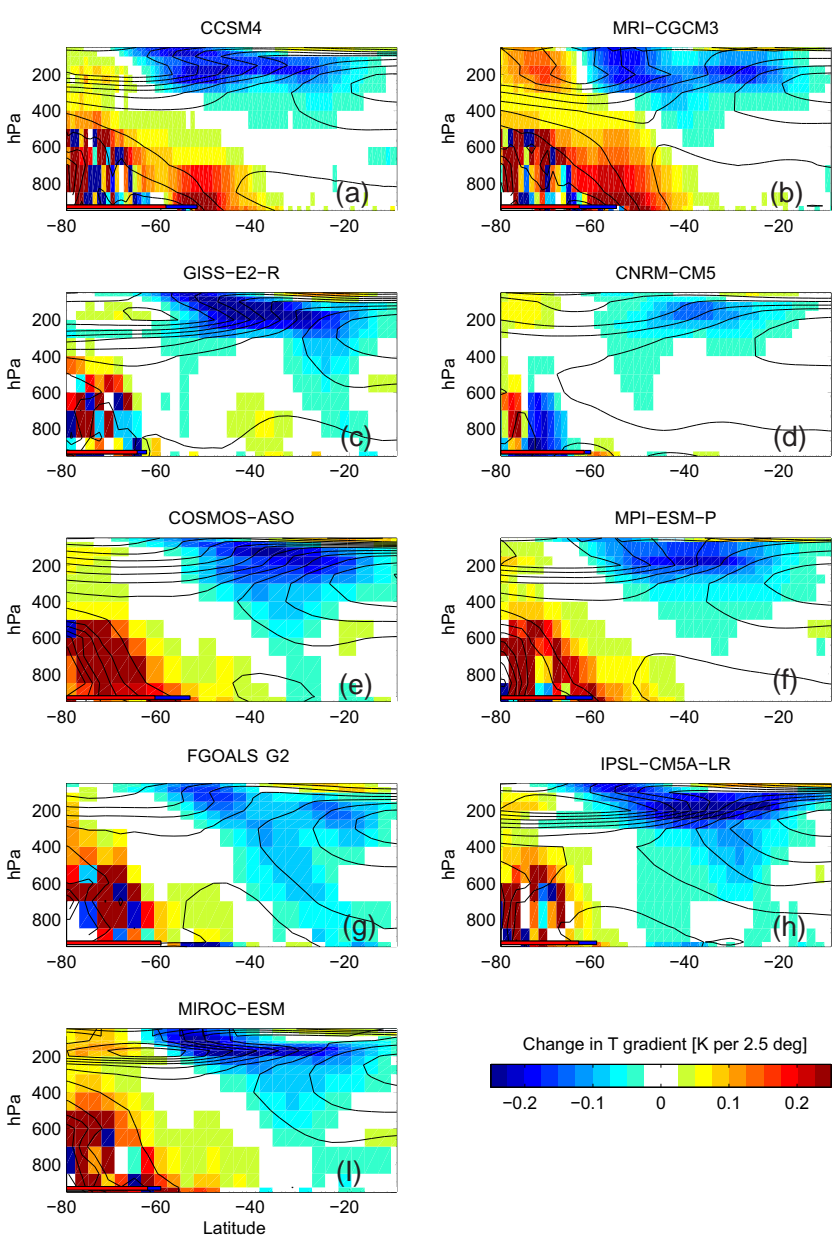

Figure 6. Change is zonal mean temperature gradient (LGM - PI) throughout the atmosphere (shaded). Black contours show the mean temperature gradient for the PI. All temperature gradients are meridional. Red and blue bars at the bottom left of each panel indicate the extent of the zonal mean sea ice for the Pi and LGM, respectively. Individual panels are labelled to indicate individual models. All values are annual means.

increased. However, the jet exhibits little response for small changes, and particularly little response if the sea ice edge is far from the jet, for example during the summer, when the sea ice edge is far from the jet maxima. The cause of the asymmetry in the atmospheric response relates to the extent to which sea ice changes affect meridional temperature gradients in the near-surface baroclinic zone. Together these results suggest that the impact of sea ice expansion during the LGM is crucial but can only be captured if the PI jet position is accurately simulated.

In addition, the offset of the fitted line in Fig. $7 \mathrm{~b}$ suggests that, without any expansion in sea ice, the jet might tend to shift towards the Equator, by around $4^{\circ}$ during the LGM. From the zero-cross of the line, we tentatively suggest that around $5^{\circ}$ of sea ice expansion is necessary to counteract this tendency. Given that the Gersonde et al. (2005) data support a latitudinal expansion of more than $5^{\circ}$, this result does suggest that a slight poleward shift (and intensification) is likely to have been a feature of the LGM jet.

\subsubsection{Sea surface temperatures changes}

If we also fit a linear model to jet shifts against sea surface temperature changes in the marginal sea ice zone, we find a weak positive relationship between sea surface temperature and $850 \mathrm{hPa}$ jet position.

Given the strong relationship between Southern Ocean surface temperature and sea ice, it is difficult to separately assess any influences of sea ice and sea surface temperature on Southern Ocean winds. However, Sime et al. (2013) conducted sensitivity experiments, using an atmospheric-only GCM, in order to attempt to elucidate these relationships. As the analysis above suggests, Sime et al. (2013) showed that cooling the Southern Ocean near the sea ice edge, around $55^{\circ} \mathrm{S}$, and extending the sea ice promotes the same response in the $850 \mathrm{hPa}$ winds.

Here, with CMIP5-PMIP3 results, we find that for the five models with PI jets which are positioned poleward of $47^{\circ} \mathrm{S}$ an average temperature change of $-1 \mathrm{~K}$ (over the Gersonde et al. (2005) data network locations) results in a $3.0^{\circ}$ poleward shift in the $850 \mathrm{hPa}$ jet $(r=0.83 ; n=5$; Fig. $7 \mathrm{c})$. Sime et al. (2013) also found that cooling near the edge of the LGM Southern Ocean sea ice and extended sea ice coverage caused a wind intensification which is largest between 56 and $58^{\circ} \mathrm{S}$. This drives the small poleward shift in the location of the winds maximum. Here, CMIP5 models with accurately positioned PI jets show a similar result.

\section{Summary and conclusions}

We have analysed the CMIP5-PMIP3 LGM and PI simulations for Southern Ocean region wind changes and examined the impacts of sea surface changes and state dependency. Nine fully independent CMIP5-PMIP3 model simulations were included in the analysis. We find a wide range of PI to LGM latitudinal shifts in the jet across the PMIP3 simulations, varying from +2.0 to $-4.5^{\circ}$ for the $850 \mathrm{hPa}$ jet, but the mean $850 \mathrm{hPa}$ jet shift for the nine models is small: $-0.21^{\circ}$. The dependence of PI to LGM jet shifts on PI jet position, referred to here as state dependency (following Bracegirdle et al., 2013), explains up to $56 \%$ of the variance in PI to LGM jet shifts in the Atlantic sector of the Southern Ocean, for $\tau_{U}$, and $41 \%$ in the Indian sector. The impact in the Pacific, however, is negligible. Since state dependence plays a weaker role in determining jet shifts and strength changes for the deglacial-warming, compared to future-warming scenarios, this implies that other factors are important in determining the LGM wind changes. Changes in surface heat fluxes, due to sea ice changes, can have very large impact on the jet, particularly when they are located close to the position of the jet, which is itself usually co-located with the maximum 

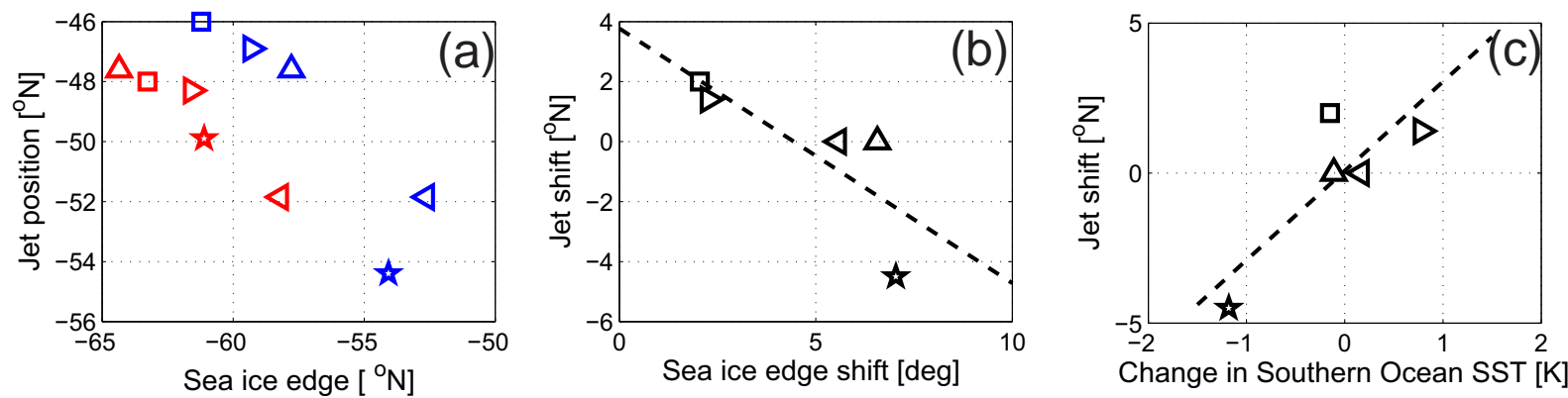

Figure 7. The relationship between sea ice, SST, and the position of the $850 \mathrm{hPa}$ jet. Symbols represent individual models as shown in Fig. 2 . All values are calculated using annual means. Red indicates the PI; blue indicates the LGM; and black indicates changes between the PI and the LGM (LGM - PI). (a) The jet position against sea ice extent (15\%), (b) jet shift against sea ice extent change, and (c) jet shift against Southern Ocean SST change. We use models where the PI jet position is poleward of $47^{\circ} \mathrm{S}$, and results are interpolated to the position of the Gersonde et al. (2005) observations before each calculation.

in the meridional temperature gradient. Given that LGM sea ice extended in the Atlantic and Indian sector close to $47^{\circ} \mathrm{S}$ and in the Pacific sector to $57^{\circ} \mathrm{S}$ (Gersonde et al., 2005), the key differences in jet shifts seem to be a dual function of state dependence and sea ice change.

All CMIP5-PMIP3 models show an LGM expansion of sea ice in the Southern Hemisphere, but there is considerable inter-model variability in the size of the expansion, which ranges from 2.1 and $7.0^{\circ}$. State dependence (PI jet position) and sea ice changes together control jet shift behaviours. Only two models, CCSM4 and MRI-CGCM3, both simulate realistically large expansions in sea ice and simulate PI jets which are south of $50^{\circ} \mathrm{S}$. These models show an increase in westerly wind speed around $55^{\circ} \mathrm{S}$ and a large PI to LGM poleward shift in the jet in MRI-CGCM3. For models that have jets positioned relatively far to the south (at $48^{\circ} \mathrm{S} \pm 0.3^{\circ}$ ) but do not correctly simulate the observed expansion in sea ice, the resultant small polar atmospheric cooling causes little change in the meridional temperature gradient. In this case, westerly wind speed simply tends to weaken over the Southern Ocean latitudes. Models that simulate a large increase in sea ice extent but have jets positioned too far towards the Equator are not sensitive to the LGM expansion of sea ice: they show a slight weakening of $U$, but no jet shifts. The jet is not significantly affected by these sea ice increases, and associated meridional temperature gradient changes, because they happen too far poleward of the baroclinic jet zone. This also fits with the study of Kidston et al. (2011), who found that whilst the jet will shift significantly poleward when the sea ice extent is substantially increased, there is little response if the sea ice edge is far from the jet.

We can generalise the relationship between sea ice extent and jet position. In models with accurately positioned PI jets, a $1^{\circ}$ difference in the sea ice edge tends to be associated with a $-0.85^{\circ}$ shift in the $850 \mathrm{hPa}$ jet. However, without any expansion in sea ice, it seems that the jet would shift towards the Equator, by around $4^{\circ}$ during the LGM. Thus we tenta- tively conclude that around $5^{\circ}$ of sea ice expansion is necessary to hold the jet in its PI position. Given that data support a northward expansion of more than $5^{\circ}$ (Gersonde et al., 2005; Roche et al., 2012), this result does suggest that a slight poleward shift (and intensification) is likely to have been a feature of the LGM jet at $850 \mathrm{hPa}$. This fits with the findings of Sime et al. (2013), who found that cooling near the edge of the LGM Southern Ocean sea ice caused a wind intensification which is largest between 56 and $58^{\circ} \mathrm{S}$. However, we emphasise that these results only apply to CMIP5 models with jets that are relatively accurately positioned i.e. those which are sensitive to the impact of sea ice changes; if the model has a jet which sits equatorward of about $47^{\circ} \mathrm{S}$ then the relationship breaks down. We note also that surface wind and shear stress changes may show different changes, so these results do not necessarily hold for all wind prognostics (Sime et al., 2013; Liu et al., 2015).

Finally, one perhaps overlooked feature of the CMIP5 present-day simulations is the proliferation of simulations which feature jets which are positioned $5^{\circ}$, or more, equatorward of the current observed position. Many CMIP5 simulations also feature jets which can be $20 \%$ too weak (Bracegirdle et al., 2013). CMIP5 models can thus simulate jets which are considerably farther equatorward and weaker than they are in our current climate. Further work could investigate whether these jet positions could themselves be taken as evidence for the physical feasibility of the large LGM jet shift hypothesis. The output from these simulations could perhaps also be compared with ongoing work on the development of reliable paleo-wind and sea ice reconstructions. Pending this, however, we conclude from our analysis of CMIP5-PMIP3 output that the LGM Southern Ocean extended sea ice coverage was most likely responsible for a small wind intensification, which was largest around $55-58^{\circ} \mathrm{S}$. Without the effect of sea ice and associated sea surface cooling, models simulate poleward-shifted westerlies in warming climates and equatorward-shifted westerlies in colder climates. However, 
the impact of LGM sea ice counters and reverses the equatorward trend in cooler climates so that the LGM winds were more likely to have also been shifted slightly poleward.

\section{Data availability}

Model data were downloaded from the publically available CMIP5 archive from https://esgf-node.ipsl.upmc.fr/projects/ esgf-ipsl/ between September and October in 2014. 
Appendix A: Observational data and calculating model-data agreements

Gersonde et al. (2005) provide LGM sea surface temperature and sea ice data from 122 Southern Ocean sediment core sites. Sime et al. (2013) suggested using simple modeldata evaluation metrics based on simple percentage statistics. Here we use a similar approach and assess sea ice modeldata agreement by classing simulated sea ice as present or absent, rather than using concentration values. Simulation results are bi-linearly interpolated to the observation site prior to the model-data assessment, analogous to the exact-metric defined by Sime et al. (2013). 
Acknowledgements. The work was funded by NERC grants NE.K004514.1 and NE/J004804/1 and also forms part of the British Antarctic Survey Polar Science for Planet Earth Programme. We acknowledge the support of the ARCHER UK National Supercomputing Service (http://www.archer.ac.uk) and the World Climate Research Programme's Working Group on Coupled Modelling, which is responsible for CMIP, and we thank the all the climate modelling groups for producing and making available their model output.

Edited by: H. Goosse

Reviewed by: three anonymous referees

\section{References}

Alexander, M. A., Bhatt, U. S., Walsh, J. E., Timlin, M. S., Miller, J. S., and Scott, J. D.: The Atmospheric Response to Realistic Arctic Sea Ice Anomalies in an AGCM during Winter, J. Climate, 17, 890-905, doi:10.1175/15200442(2004)017\%3C0890:tartra\%3E2.0.co;2, 2004.

Bracegirdle, T. J., Shuckburgh, E., Sallee, J.-B., Wang, Z., Meijers, A. J. S., Bruneau, N., Phillips, T., and Wilcox, L. J.: Assessment of surface winds over the Atlantic, Indian, and Pacific Ocean sectors of the Southern Ocean in CMIP5 models: historical bias, forcing response, and state dependence, J. Geophys. Res.-Atmos., 118, 547-562, doi:10.1002/jgrd.50153, 2013.

Braconnot, P., Otto-Bliesner, B., Harrison, S., Joussaume, S., Peterchmitt, J.-Y., Abe-Ouchi, A., Crucifix, M., Driesschaert, E., Fichefet, Th., Hewitt, C. D., Kageyama, M., Kitoh, A., Laîné, A., Loutre, M.-F., Marti, O., Merkel, U., Ramstein, G., Valdes, P., Weber, S. L., Yu, Y., and Zhao, Y.: Results of PMIP2 coupled simulations of the Mid-Holocene and Last Glacial Maximum Part 1: experiments and large-scale features, Clim. Past, 3, 261277, doi:10.5194/cp-3-261-2007, 2007.

Braconnot, P., Harrison, S. P., Kageyama, M., Bartlein, P. J., Masson-Delmotte, V., Abe-Ouchi, A., Otto-Bliesner, B., and Zhao, Y.: Evaluation of climate models using palaeoclimatic data, Nature Climate Change, 2, 417-424, doi:10.1038/nclimate1456, 2012.

Brayshaw, D. J., Hoskins, B., and Blackburn, M.: The Storm-Track Response to Idealized SST Perturbations in an Aquaplanet GCM, J. Atmos. Sci., 65, 2842-2860, doi:10.1175/2008jas2657.1, 2008.

Chavaillaz, Y., Codron, F., and Kageyama, M.: Southern westerlies in LGM and future (RCP4.5) climates, Clim. Past, 9, 517-524, doi:10.5194/cp-9-517-2013, 2013.

Chen, G., Plumb, R. A., and Lu, J.: Sensitivities of zonal mean atmospheric circulation to SST warming in an aqua-planet model, Geophys. Res. Lett., 37, L12701, doi:10.1029/2010g1043473, 2010.

Denton, G. H., Anderson, R. F., Toggweiler, J. R., Edwards, R. L., Schaefer, J. M., and Putnam, A. E.: The Last Glacial Termination, Science, 328, 1652-1656, doi:10.1126/science.1184119, 2010.

d'Orgeville, M., Sijp, W. P., England, M. H., and Meissner, K. J.: On the control of glacial-interglacial atmospheric $\mathrm{CO}_{2}$ variations by the Southern Hemisphere westerlies, Geophys. Res. Lett., 37, L21703, doi:10.1029/2010g1045261, 2010.
Ferrari, R., Jansen, M. F., Adkins, J. F., Burke, A., Stewart, A. L., and Thompson, A. F.: Antarctic sea ice control on ocean circulation in present and glacial climates, P. Natl. Acad. Sci. USA, 111, 8753-8758, doi:10.1073/pnas.1323922111, 2014.

Gersonde, R., Crosta, X., Abelmann, A., and Armand, L.: Sea surface temperature and sea ice distribution of the last glacial. Southern Ocean - A circum-Antarctic view based on siliceous microfossil records, Quaternary Sci. Rev., 24, 869-896, 2005.

Hodgson, D. A. and Sime, L. C.: Palaeoclimate: Southern westerlies and $\mathrm{CO}_{2}$, Nat. Geosci., 3, 666-667, doi:10.1038/ngeo970, 2010.

Kidston, J. and Gerber, E. P.: Intermodel variability of the poleward shift of the austral jet stream in the CMIP3 integrations linked to biases in 20th century climatology, Geophys. Res. Lett., 37, L09708, doi:10.1029/2010g1042873, 2010.

Kidston, J., Taschetto, A. S., Thompson, D. W. J., and England, M. H.: The influence of Southern Hemisphere sea-ice extent on the latitude of the mid-latitude jet stream, Geophys. Res. Lett., 38, L15804, doi:10.1029/2011GL048056, 2011.

Kim, S., Flato, G., and Boer, G.: A coupled climate model simulation of the Last Glacial Maximum, Part 2: approach to equilibrium, Clim. Dynam., 20, 635-661, 2003.

Kohfeld, K. E., Quere, C. L., Harrison, S. P., and Anderson, R. F.: Role of Marine Biology in Glacial-Interglacial $\mathrm{CO}_{2}$ Cycles, Science, 308, 74-78, doi:10.1126/science.1105375, 2005.

Kohfeld, K. E., Graham, R. M., de Boer, A. M., Sime, L. C., Wolff, E. W., Le Quéré, C., and Bopp, L.: Southern Hemisphere westerly wind changes during the Last Glacial Maximum: paleo-data synthesis, Quaternary Science Reviews, 68, 76-95, doi:10.1016/j.quascirev.2013.01.017, 2013.

Lamy, F., Gersonde, R., Winckler, G., Esper, O., Jaeschke, A., Kuhn, G., Ullermann, J., Martinez-Garcia, A., Lambert, F., and Kilian, R.: Increased Dust Deposition in the Pacific Southern Ocean During Glacial Periods, Science, 343, 403-407, doi:10.1126/science.1245424, 2014.

Lee, S.-Y., Chiang, J. C. H., Matsumoto, K., and Tokos, K. S.: Southern Ocean wind response to North Atlantic cooling and the rise in atmospheric $\mathrm{CO}_{2}$ : Modeling perspective and paleoceanographic implications, Paleoceanography, 26, PA1214, doi:10.1029/2010pa002004, 2011.

Liu, W., Lu, J., Leung, Xie, S.-P., Liu, Z., and Zhu, J.: The decorrelation of westerly winds and westerly-wind stress over the Southern Ocean during the Last Glacial Maximum, Clim. Dynam., 45, 3157-3168, doi:10.1007/s00382-015-2530-4, 2015.

MARGO Project Members: Constraints on the magnitude and patterns of ocean cooling at the Last Glacial Maximum, Nat. Geosci., 2, 127-132, doi:10.1038/ngeo411, 2009.

Menviel, L., Timmermann, A., Mouchet, A., and Timm, O.: Climate and marine carbon cycle response to changes in the strength of the Southern Hemispheric westerlies, Paleoceanography, 23, PA4201, doi:10.1029/2008PA001604, 2008.

MITgcm Group: MITgcm user manual, online documentation, Tech. rep., MIT-EAPS, Cambridge, USA, 2013.

Otto-Bliesner, B. L., Brady, E., Clauzet, G., Thomas, R., Levis, S., and Kothavala, Z.: Last glacial maximum and Holocene climate in CCSM3, J. Climate, 19, 2526-2544, 2006.

Roche, D. M., Crosta, X., and Renssen, H.: Evaluating Southern Ocean sea-ice for the Last Glacial Maximum and pre-industrial climates: PMIP-2 models and data evidence, Quaternary Sci. Revi., 56, 99-106, doi:10.1016/j.quascirev.2012.09.020, 2012. 
Rojas, M.: Sensitivity of Southern Hemisphere circulation to LGM and $4 \times$ CO 2 climates, Geophys. Res. Lett., 40, 965-970, doi:10.1002/grl.50195, 2013.

Sigman, D. M., Hain, M. P., and Haug, G. H.: The polar ocean and glacial cycles in atmospheric $\mathrm{CO}_{2}$ concentration, Nature, 466, 47-55, doi:10.1038/nature09149, 2010.

Sime, L. C., Kohfeld, K. E., Le Quéré, C., Wolff, E. W., de Boer, A. M., Graham, R. M., and Bopp, L.: Southern Hemisphere westerly wind changes during the Last Glacial Maximum: model-data comparison, Quaternary Sci. Rev., 64, 104-120, doi:10.1016/j.quascirev.2012.12.008, 2013.

Swart, N. C. and Fyfe, J. C.: Observed and simulated changes in the Southern Hemisphere surface westerly wind-stress, Geophys. Res. Lett., 39, L16711, doi:10.1029/2012g1052810, 2012.

Taylor, K. E., Stouffer, R. J., and Meehl, G. A.: An Overview of CMIP5 and the Experiment Design, B. Am. Meteorol. Soc., 93, 485-498, doi:10.1175/bams-d-11-00094.1, 2011.
Toggweiler, J. R., Russell, J., and Carson, S. R.: Midlatitude westerlies, atmospheric $\mathrm{CO}_{2}$, and climate change during the ice ages, Paleoceanography, 21, PA2005, doi:10.1029/2005PA001154, 2006.

Tschumi, T., Joos, F., and Parekh, P.: How important are Southern Hemisphere wind changes for low glacial carbon dioxide? A model study, Paleoceanography, 23, PA4208, doi:10.1029/2008pa001592, 2008.

Völker, C. and Köhler, P.: Responses of ocean circulation and carbon cycle to changes in the position of the Southern Hemisphere westerlies at Last Glacial Maximum, Paleoceanography, 28, 726-739, doi:10.1002/2013pa002556, 2013.

Wilcox, L. J., Charlton-Perez, A. J., and Gray, L. J.: Trends in Austral jet position in ensembles of high- and low-top CMIP5 models, J. Geophys. Res., 117, D13115, doi:10.1029/2012jd017597, 2012. 